\title{
Biological significance of recombination-activating gene 1, RAG1 in optic nerve neuropathy
}

\author{
Takao Hirano $^{1}$, Tomoko Nakamura-Yanagidaira ${ }^{1,2}$ and Takuma Hayashi ${ }^{3 *}$ \\ ${ }^{1}$ Department of Ophthalmology, Shinshu University Graduate School of Medicine, 3-1-1 Asahi, Matsumoto, Nagano 390-8621, Japan \\ ${ }^{2}$ Department of Ophthalmology, Japanese Red Cross Society, Azumino Hospital, 5685 Toyoshina, Azumino, Nagano 399-8292, Japan \\ ${ }^{3}$ National Hospital Organization Kyoto Medical Center. 1-1 Fukushi-ku, Kyoto-city, Kyoto 612-8555, Japan
}

\begin{abstract}
Although the transcription factor, nuclear factor-kappa-B $(\mathrm{NF}-\kappa \mathrm{B})$ is known to regulate programed-cell death and survival, its precise role in cell death within the central nervous system (CNS) remains unknown. We previously reported that mice with a homozygous deficiency for $N f-\kappa b 1 p 50$ spontaneously developed optic neuropathy. We investigated the expression and activation of pro-apoptotic factor(s), which mediate optic nerve neuropathy in $N f-\kappa b 1 p 50$-deficient mice. Recombination activating gene 1 (RAG1) is known to control the recombination of immunoglobulin $V(D) J$. Experiments with genetically engineered mice revealed the involvement of RAG1 expression in the programmed-cell death of POU domain protein (POU4f2)/brain-specific homeobox 3A (BRN3a)-positive retinal ganglion cells (RGCs), and also showed the specific effects of a $N f-\kappa b 1 p 50$ - deficient on the activation of Rag1 gene transcription. Furthermore, a genetic analysis of murine neuronal stem-like cells clarified the biological significance of RAG1 in N-methyl-D-aspartate (NMDA)-induced neuronal cell death. The apoptotic inducing factors were detected in human cell line expressing the external molecule of RAG1, and human histopathological examinations with retina tissues revealed the expression of RAG1 in RGCs. Recent studies indicated that RAG1 played a key role in optic nerve neuropathy as a pro-apoptotic candidate in $N f-\kappa b 1 p 50$ deficient mice. These results may lead to new therapeutic targets in optic nerve neuropathy.
\end{abstract}

\section{Introduction}

The intracellular pathways related to cell survival regulate neuronal physiology during embryonic development as well as the pathogenesis of various neurodegenerative disorders. The nuclear factor-kappa-B (NF$\kappa \mathrm{B})$ signal pathway was discovered in 1986 as a transcription modulator of the $\kappa$-light chain of B lymphocyte immunoglobulins [1]. Subsequent studies have shown that NF- $\mathrm{kB}$ is a ubiquitously expressed dimeric transcription factor involved in numerous cellular processes, such as inflammation, programmed cell death, and tumorigenesis. NF- $\kappa \mathrm{B}$ is a dimer composed of members of the REL transcriptional factor family [2]. The classical NF- $\kappa B$ family, which is primarily composed of NF$\kappa \mathrm{B} 1 \mathrm{p} 50 / \mathrm{RELA}(\mathrm{p} 65)$ heterodimers, has been detected in almost animal cell types and is involved in cellular responses to stimuli such as stress and cytokines [3]. Accordingly, the impaired regulation of NF- $\kappa B$ has been linked to various diseases, including oncogenesis, inflammatory disorders, and autoimmune diseases, as well as deficiencies in the processes of synaptic plasticity and memory [4]. NF- $\kappa B$ family also plays important roles in central nervous system (CNS) development and pathology by influencing neuronal apoptosis, neurite outgrowth, and synaptic plasticity $[5,6]$. However, the range of cellular signals and transduction mechanisms that regulate activation of NF- $\kappa B$ family in neurons is broad and complex. Genetically modified mice have been extensively used to assess different gene components in the NF- $\kappa \mathrm{B}$ signal pathway. For instance, $N f$ - $\kappa b 1 p 50$-deficient mice, which are mice with a homozygous deficiency for $N f-\kappa b 1 p 50$, exhibited the agerelated degeneration of neuronal and non-neuronal cells, and defective activation of NF- $\kappa \mathrm{B}$ resulted in apoptosis in the striatal neurons of a Huntington disease model [7-9]. Activated RELA(p65) has been suggested to glutamate-induced neurotoxicity, N-methyl-D-aspartate (NMDA)-induced retinal neuronal cell death, retinal ischemia, and reperfusion injury in the CNS [10-13]. We previously reported that the number of retinal ganglion cells (RGCs) in Nf-kb1p50-deficient mice was significantly lower than that in its parental mice, $N f-\kappa b 1 p 50$-wild type mice, suggesting that these animals exhibited features resembling those of human non-tension glaucoma (NTG) [14,15]. However, the precise role of NF- $\mathrm{BB}$ in cell death within the CNS remains controversial. Therefore, we searched for a new target related to NF- $\kappa \mathrm{B}$ signal pathways in optical neurons.

\section{Physiological significance of RAG1 in neuropathy}

$\mathrm{NF}-\kappa \mathrm{B}$ was reportedly relevant in the B-cell receptor-mediated regulation of recombination activating gene (Rag) locus transcription [16]. Recent studies suggested that immediately activated NF- $\kappa B$ signal pathways may facilitate quick antigen receptor-regulated changes in RAG expression, which is important for editing [16]. Rag genes encode two enzymes that play key roles in the adaptive immune system: both RAG1 and RAG2 mediate the recombination of V(D)J, a process that is essential for the maturation of $\mathrm{B}$ and $\mathrm{T}$ lymphocytes in the development and maturation of lymphocytes $[17,18]$. RAGs have been detected not only in the immune network systems of mammals and amphibians, but also in their nervous systems; Rag1 transcripts have been found in the murine CNS, particularly in areas of high neural density, such as the cerebellum and hippocampal formation [9,19-21]. RAG1 may

*Correspondence to: Takuma Hayashi, National Hospital Organization Kyoto Medical Center. 1-1 Fukushi-ku, Kyoto-city, Kyoto 612-8621, Japan, E-mail: yoyoyo224@hotmail.com

Key words: RAG1, NF- $\kappa B 1 p 50$, programmed cell death, RGCs, optic neuropathy

Received: May 15 2020; Accepted: June 08, 2020; Published: June 12, 2020 
function in neurons to site-specifically recombine elements of the neuronal genome or prevent detrimental alternations in the genomes of long-lived cells. Although the role of the RAG1 locus in the CNS is currently unclear, RAGs are known to be directly regulated by NF$\kappa B$ [16]. Inhibition of NF- $\kappa B$ kinase subunit beta (IKK- $\beta$ ) and NF- $\kappa B$ delays ageing and increases lifespan [22]. Based on the above-described findings, we focused on RAG1 as a novel candidate target related to $\mathrm{NF}-\kappa \mathrm{B}$ signal pathways in neurons using $\mathrm{Nf}$ - $\kappa$ b1p50-deficient mice as a model of optic nerve neuropathy. Since no studies have been published on the expression of RAG1 in the visual system, we first confirmed the presence of RAG1, but not the RAG2 transcript in murine and human RGCs (Figure 1). The loss of RAG1 in Nf- $k b 1 p 50$-deficient mice resulted in a decrease in optic nerve neuropathy. In vertebrate embryonic development, the retina and optic nerve originate as outgrowths of the developing brain, and, thus, the retina is part of the CNS. In further experiments, three-dimensional cultures of mouse embryonic stem cell aggregates have demonstrated the autonomous formation of the optic cup, which develops into the outer and inner layers of the retina structure from brain balls [23]. Glutamate is a major excitatory neurotransmitter in vertical pathways through the retina, wherein RGCs first express the NMDA/glutamate receptors that are typical in the brain $[24,25]$. Since the brain and retina have a close relationship in genesis and neurotransmission, it is plausible that RAG1, which has been detected in the hippocampus, is also expressed in the retina.

We assessed the precise role of RAG1 in the retina using experiments with $N f$ - $\kappa b 1 p 50$-deficient mice, which exhibit age-dependent decreases in RGCs. A genetically lack of RAG1 in Nf- $\kappa b 1 p 50$-deficient mice diminished the loss of RGC, which was confirmed by several lines of evidence in the present studies. These results promoted us to speculate that RAG1 may play a physiological role in the programmed cell death of RGCs, which was accelerated by RELA(p65)/c-REL, in Nf- $\kappa b 1 p 50$ deficient mice. We proposed that RAG1 specifically influence apoptotic signal pathway in the nucleus [26] (Figure 2).

Many questions remain regarding the molecular mechanisms involved in physiological functions of RAG1 in the retina. The biological evidence for this lies in studies of the molecular structure of the recombinase enzymes themselves; although both RAG1 and RAG2 share several roles, i.e., DNA cleavage and rearrangement of $\mathrm{V}(\mathrm{D})$ J recombination, only RAG1 molecule contained the catalytic DNAbinding core of the recombinase $[27,28]$. Kelch motifs, which mediate the interactions of RAG1 and RAG2, have been observed in numerous proteins, and RAG1 may interact with an identified protein via a kelch motif in the retina [29]. As in the mouse retina, we confirmed the intracellular localization of RAG1, but not RAG2, in RGCs in the human retina and other types of neuron [26,30-31] (Figure 2). A protein homology studies revealed that the human RAG1 molecule was $90 \%$ homologous with its mouse orthologue, the catalytic domains, zincfinger, recombinase, and RING-finger in RAG1 molecule appeared to be conserved between species. These results indicated the physiological significance of RAG1 observed in mice may extend to the regulation of human RGC survival. Further studies on the physiological role of RAG1 in RGCs are expected to contribute to the development of

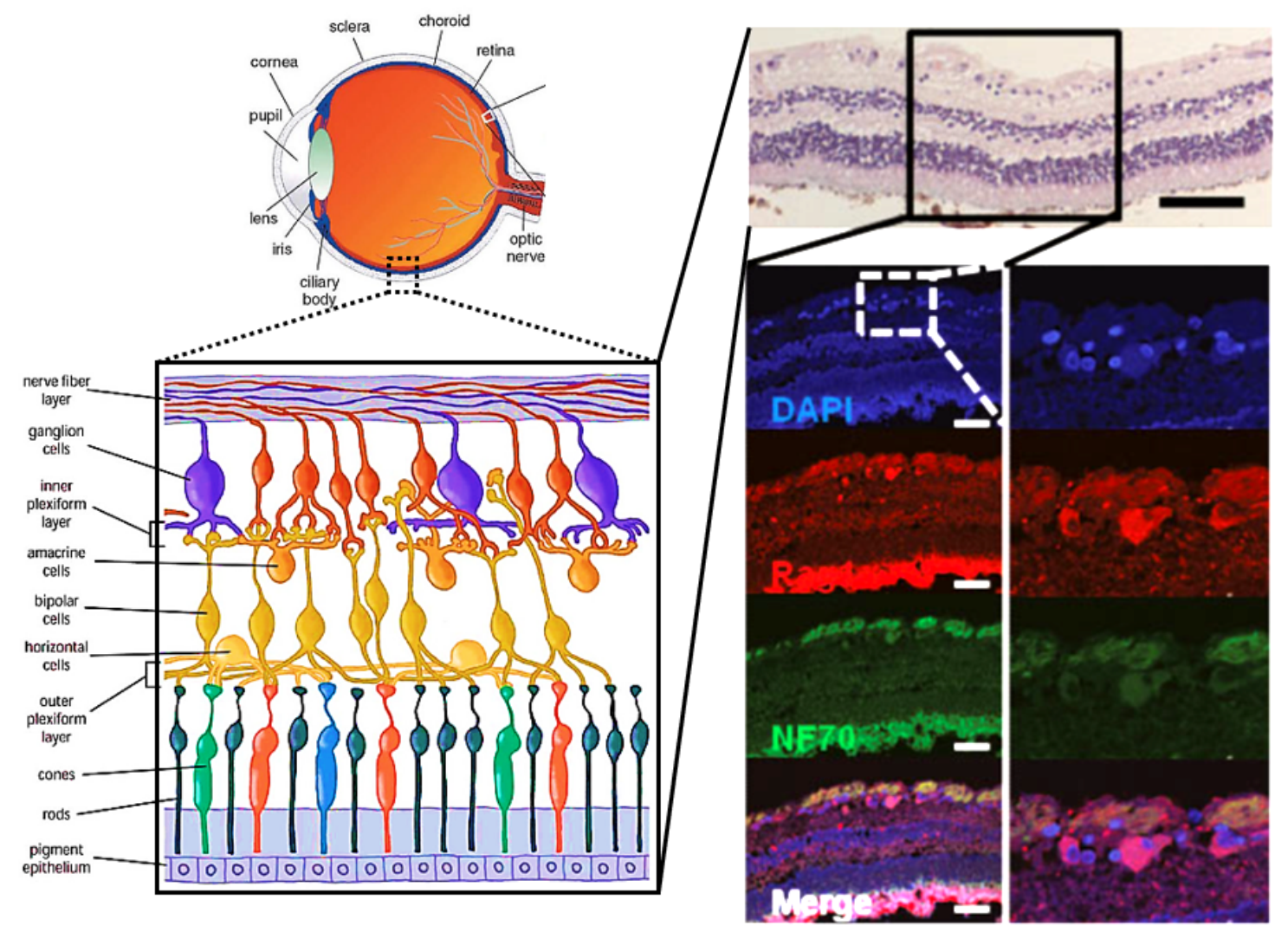

Figure 1. Rag1 expression in tissue sections obtained from the human retina. (A) HE is staining (upper panel) and IHC analysis (lower panel) of DAPI, Rag1 and NF70 in human retinal preparations. Rag1 was detected in the GCL, whereas normal rabbit (red) and mouse (green) IgG were not. Scale bar (black): $100 \mathrm{~mm}$; Scale bar (white): 50 mm. Part of figure is adapted from doi: $10.1111 /$ febs. 13109 


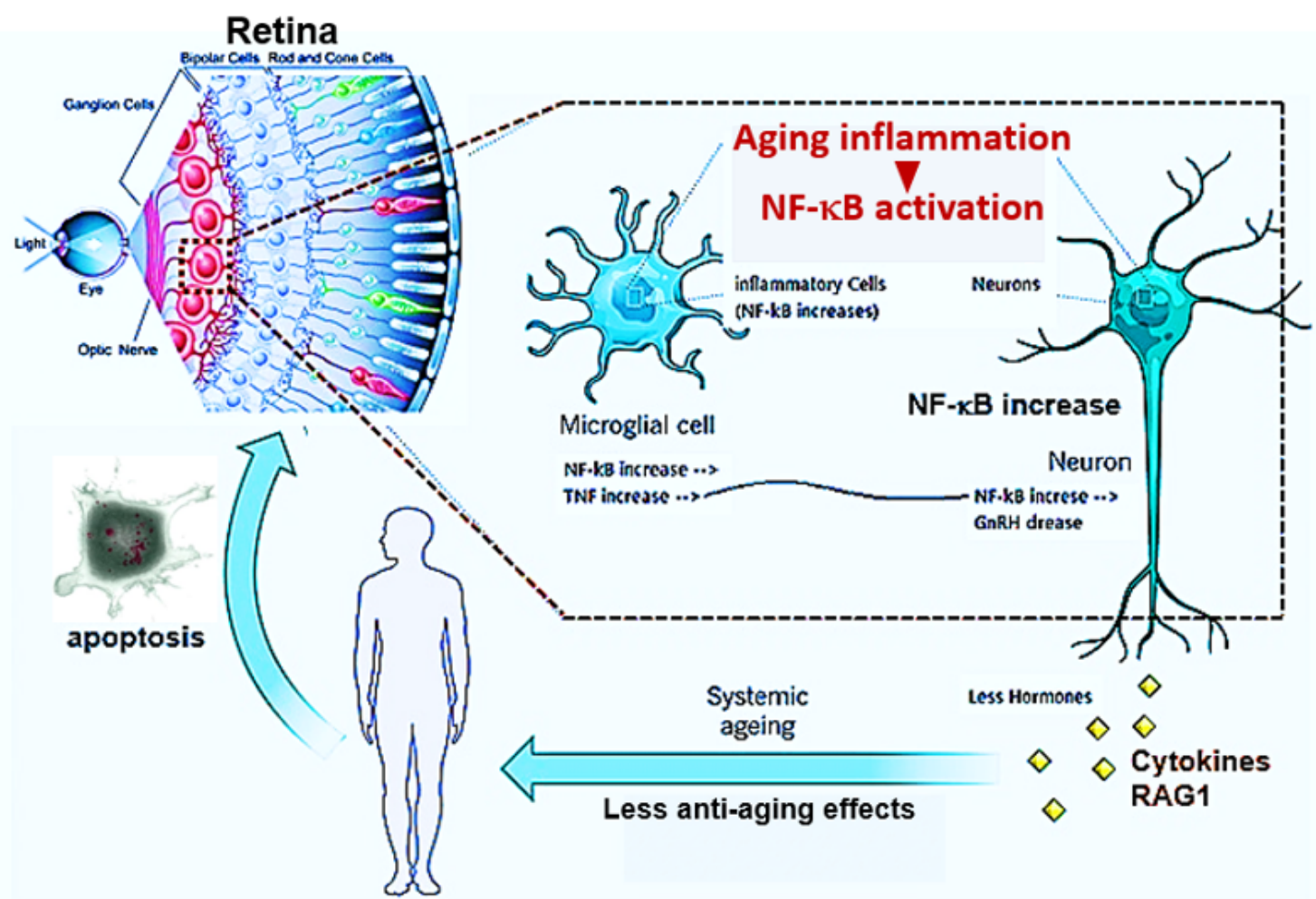

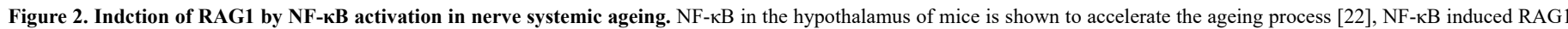
activation may mediate optic neuropathy

preventive and therapeutic treatments for human NTG and optic nerve neuropathy.

\section{Conclusion}

As in the mouse retina, we confirmed the localization of RAG1, but not RAG2, in human RGCs. The catalytic domains, zinc-finger, recombinase and RING-finger in the RAG1 molecule appear to be conserved between species. These results indicated the physiological significance of RAG1 in human RGC survival, similarly to that in murine RGCs. We conclude that RAG1 may also be involved in the programmed cell death of RGCs in the human glaucomatous retina. Further studies on the role of RAG1 in RGCs are expected to contribute to the development of preventive and therapeutic treatments for human glaucoma.

\section{Acknowledgment}

The authors thank Dr Rick A. Young for critical reading of the manuscript and valuable intellectual discussions. The research is financed by: This work was supported by JSPS KAKEN Grant Numbers 23390400 and 24659759. (National Institution of Health: The Japan Society for the Promotion of Science)

\section{Conflict of interest}

The authors declare that they do not have any conflict of interest in undertaking this review. The funders had no role in study design, data collection and analysis, decision to publish, or preparation of the manuscript. The material (manuscript and figure) is original research, has not been previously published, and has not been submitted for publication elsewhere while under consideration.

\section{Author contributions}

All authors had full access to the data in the study and take responsibility for the integrity of the data and accuracy of the data analysis. Conceptualization, T.H. and T.H.; Writing-Original Draft, T.N-Y. and I.K.; Writing-Review \& Editing, I.K.; Visualization, T.H. and T.H.; Supervision, T.H. and T.H.; Funding Acquisition, T.H. and T.N-Y.

\section{References}

1. Sen R, Baltimore D (1986) Multiple nuclear factors interact with the immunoglobulin enhancer sequences. Cell 46: 705-716. [Crossref]

2. Huxford T, Malek S, Ghosh G (1999) Structure and mechanism in NF-kappa B/I kappa B signaling. Cold Spring Harbor Symposia on Quantitative Biology 64: 533-540. [Crossref]

3. Sha WC, Liou HC, Tuomanen EI, Baltimore D (1995) Targeted disruption of the p50 subunit of NF-kappa B leads to multifocal defects in immune responses. Cell 80: 321 330 .

4. Hoffmann A, Leung TH, Baltimore D (2003) Genetic analysis of NF-kappaB/Rel transcription factors defines functional specificities. The EMBO $J$ 22: 5530-5539. [Crossref]

5. Baeuerle PA, Baltimore D (1988) I kappa B: a specific inhibitor of the NF-kappa B transcription factor. Science 242: 540-546. [Crossref]

6. Mattson MP, Meffert MK (2006) Roles for NF-kappaB in nerve cell survival, plasticity, and disease. Cell Death Differ 13: 852-860. [Crossref]

7. Lu ZY, Yu SP, Wei JF, Wei L (2006) Age-related neural degeneration in nuclear-factor kappaB p50 knockout mice. Neuroscience 139: 965-978. [Crossref]

8. Yu Z, Zhou D, Bruce-Keller AJ, Kindy MS, Mattson MP (1999) Lack of the p50 subunit of nuclear factor-kappaB increases the vulnerability of hippocampal neurons to excitotoxic injury. $J$ Neurosci 19: 8856-8865. [Crossref]

9. Fang M, Yin Y, Chen H, Hu Z, Davies H, et al. (2013) Contribution of Rag1 to spatial memory ability in rats. Behav Brain Res 236: 200-209. [Crossref] 
10. Fan W, Cooper NG (2009) Glutamate-induced NFkappaB activation in the retina. Invest Ophthalmol Vis Sci 50: 917-925. [Crossref]

11. Grilli M, Pizzi M, Memo M, Spano P (1996) Neuroprotection by aspirin and sodium salicylate through blockade of NF-kappaB activation. Science 274: 1383-1385. [Crossref]

12. Nakai M, Qin ZH, Chen JF, Wang Y, Chase TN (2000) Kainic acid-induced apoptosis in rat striatum is associated with nuclear factor-kappaB activation. $J$ Neurochem 74 647-658. [Crossref]

13. Chen YG, Zhang C, Chiang SK, Wu T, Tso MO (2003) Increased nuclear factor-kappa B p65 immunoreactivity following retinal ischemia and reperfusion injury in mice. $J$ Neurosci Res 72: 125-131. [Crossref]

14. Takahash Y, Katai N, Murata T, Taniguchi SI, Hayashi T (2007) Development of spontaneous optic neuropathy in NF-kappaBetap50-deficient mice: requirement for NF-kappaBetap50 in ganglion cell survival. Neuropathol Appl Neurobiol 33: 692-705. [Crossref]

15. Nakamura-Yanagidaira T, Takahashi Y, Sano K, Murata, T, Hayashi T (2011) Development of spontaneous neuropathy in NF-kBp50-deficient mice by calcineurinsignal involving impaired NF-אB activation. Mol Vis 17: 2157-2170. [Crossref]

16. Verkoczy L, Ait-Azzouzene D, Skog P, Martensson A, Lang J, et al. (2005) A role for nuclear factor kappa $\mathrm{B} / \mathrm{rel}$ transcription factors in the regulation of the recombinase activator genes. Immunity 22: 519-531. [Crossref]

17. Mombaerts P, Iacomini J, Johnson RS, Herrup K, Tonegawa S, et al. (1992) RAG1-deficient mice have no mature B and T lymphocytes. Cell 68: 869-877. [Crossref]

18. Oettinger MA, Schatz DG, Gorka C, Baltimore D (1990) RAG-1 and RAG-2, adjacent genes that synergistically activate V(D)J recombination. Science 248: 1517-1523.

19. Chun JJ, Schatz DG, Oettinger MA, Jaenisch R, Baltimore D (1991) The recombination activating gene-1 (RAG-1) transcript is present in the murine central nervous system. Cell 64: 189-200.

20. Rattazzi L, Cariboni A, Poojara R, Shoenfeld Y, D'Acquisto F (2015) Impaired sense of smell and altered olfactory system in RAG-1( -$)$ immunodeficient mice. Front Neurosci 9: 318. [Crossref]
21. Wang X, Su H, Bradley A (2002) Molecular mechanisms governing Pcdh-gamma gene expression: evidence for a multiple promoter and cis-alternative splicing model. Genes Dev 16: 1890-1905. [Crossref]

22. Zhang G, Li J, Purkayastha S, Tang Y, Zhang H, et al. (2013) Hypothalamic programming of systemic ageing involving IKK- $\beta$, NF- $\mathrm{kB}$ and GnRH. Nature 497 : 211-216. [Crossref]

23. Eiraku M, Takata N, Ishibashi H, Kawada M, Sakakura E, et al. (2011) Selforganizing optic-cup morphogenesis in three-dimensional culture. Nature 472: 5156. [Crossref]

24. Massey SC, Miller RF (1988) Glutamate receptors of ganglion cells in the rabbit retina: evidence for glutamate as a bipolar cell transmitter. $J$ Physiol 405: 635-55. [Crossref]

25. Yazejian B, Fain GL (1992) Excitatory amino acid receptors on isolated retinal ganglion cells from the goldfish. J Neurophysiol 67: 94-107. [Crossref]

26. Hirano T, Murata T, Hayashi T (2015) Physiological significance of Rag1 in neuronal death, especially optic neuropathy. FEBS J 282: 129-141. [Crossref]

27. Fugmann SD, Lee AI, Shockett PE, Villey IJ, Schatz DG (2000) The RAG proteins and $\mathrm{V}(\mathrm{D}) \mathrm{J}$ recombination: complexes, ends, and transposition. Annu Rev Immunol 18 : 495-527. [Crossref]

28. Zhou L, Mitra R, Atkinson PW, Hickman AB, Dyda F, et al. (2004) Transposition of hAT elements links transposable elements and V(D)J recombination. Nature 432: 995 1001. [Crossref]

29. Prag S, Adams JC (2003) Molecular phylogeny of the kelch-repeat superfamily reveals an expansion of BTB/kelch proteins in animals. BMC Bioinfor 4: 42. [Crossref]

30. Fang M, Yin Y, Chen H, Hu Z, Davies H, et al. (2013) Contribution of Rag1 to spatial memory ability in rats. Behav Brain Res 236: 200-209. [Crossref]

31. Dutta D, Kundu M, Mondal S, Roy A, Ruehl S, et al. (2019) RANTES-induced invasion of Th17 cells into substantia nigra potentiates dopaminergic cell loss in MPTP mouse model of Parkinson's disease. Neurobiol Dis 132: 104575. [Crossref]

Copyright: (C2020 Hirano T. This is an open-access article distributed under the terms of the Creative Commons Attribution License, which permits unrestricted use, distribution, and reproduction in any medium, provided the original author and source are credited. 